\title{
Effect of angiotensin converting enzyme inhibitors on periprocedural myocardial infarction in patients with metabolic syndrome
}

\author{
Ozgur Ulas Ozcan, Elif Ezgi Ustun, Sadi Gulec, Demet Menekse Gerede, \\ Huseyin Goksuluk, Veysel Kutay Vurgun, Cansin Tulunay Kaya, Cetin Erol \\ Cardiology Department, Ankara University, Ankara, Turkey
}

\begin{abstract}
Background: Metabolic syndrome (MetS) has been reported as a risk factor for cardiovascular events. The aim of the present study is to investigate the association between chronic angiotensin-converting enzyme inhibitors (ACE-I) therapy and the rate of periprocedural myocardial infarction (PMI) after elective coronary stenting among patients with MetS.

Methods: The inclusion criteria were MetS and plan for elective percutaneous coronary intervention. To assess the effect of ACE-I treatment on the incidence of PMI, measurements of cardiac biomarkers (CK-MB mass and troponin I) were performed at baseline and $24 \mathrm{~h}$ after the procedure.

Results: A total of 459 patients fulfilling the inclusion criteria were recruited to chronic ACE-I treatment and ACE-I naive groups in a 2/1 ratio. Baseline troponin I and CK-MB levels were similar in both treatment groups, whereas they were significantly lower in ACE-I group $24 \mathrm{~h}$ after the procedure. Univariate analysis identified body mass index (BMI), LDL cholesterol, nitrate and ACE-I use as significant factors for the development of PMI. Multivariate regression model revealed that body mass index increased and use of nitrate and ACE-I decreased the probability of PMI independent from confounding factors (OR 1.14, 95\% CI 1.05-1.23, $p=0.002$ for BMI; OR 0.26, 95\% CI 0.14-0.48, $p=0.01$ for nitrate use, OR 0.51, 95\% CI $0.27-0.93, p=0.03$ for ACE-I use).
\end{abstract}

Conclusions: This prospective observational cohort trial demonstrated that chronic ACE-I therapy was an independent predictor for reduced PMI among patients with MetS who underwent elective coronary intervention. (Cardiol J 2015; 22, 3: 323-329)

Key words: angiotensin converting enzyme inhibitor, coronary artery disease, metabolic syndrome, percutaneous coronary intervention, periprocedural myocardial infarction

\section{Introduction}

The metabolic syndrome (MetS) is a constellation of risk factors including central obesity, insulin resistance, dyslipidemia, hypertension and impaired glucose tolerance, which are highly associated with increased mortality and morbidity of cardiovascular diseases [1-3]. Although the pathogenesis of MetS remains unclear, abdominal obesity and insulin resistance have been suggested

\footnotetext{
Address for correspondence: Ozgur Ulas Ozcan, MD, Ankara University, School of Medicine, Cardiology Department, Ovecler 1042 ${ }^{\text {nd }}$ street 45/14. 06460 Cankaya-Ankara, Turkey, tel: +90 50570776 70, fax: +90 3122647800 , e-mail: ozgurulasozcan@yahoo.com.tr
}

Received: 12.09.2014 Accepted: 14.11.2014 
to be the underlying feature [4]. Patients with MetS have increased incidence of adverse cardiovascular events compared to those without MetS after coronary stent implantation [5].

Periprocedural myocardial infarction (PMI) occurs in up to $5-30 \%$ of patients after percutaneous coronary interventions (PCI) $[6,7]$ and predicts adverse events and prognosis even after apparently successful procedures [8, 9].

Angiotensin-converting enzyme inhibitors (ACE-I) have favorable effects on insulin resistance [10], endothelial functions [11] and atherosclerosis $[12,13]$. Whether ACE-I therapy can also protect patients with MetS before elective coronary stenting remains unknown.

On the basis of these data, we hypothesized that chronic ACE-I therapy before elective coronary interventions might reduce the incidence of PMI among patients with MetS.

\section{Methods}

An observational prospective cohort study was designed to determine whether chronic ACE-I treatment reduces the rate of PMI among patients with MetS. All consecutive patients scheduled for elective coronary stenting between February and June 2014 were screened for eligibility. The inclusion criteria were MetS and plan for elective percutaneous coronary stenting.
MetS was defined according to the third report of the National Cholesterol Education Program Expert Panel on detection, evaluation and treatment of high blood cholesterol in adults (ATP-III), as the presence of 3 or more of these components: high fasting glucose (fasting serum glucose $\geq 100 \mathrm{mg} / \mathrm{dL}$ or drug treatment for elevated blood glucose), abdominal obesity (given as waist circumference $>102 \mathrm{~cm}$ in men and $>88 \mathrm{~cm}$ in women), high blood pressure $(\geq 130 / \geq 85 \mathrm{~mm} \mathrm{Hg}$ or drug treatment for hypertension), hypertriglyceridemia (serum triglycerides $\geq 150 \mathrm{mg} / \mathrm{dL}$ ), and low highdensity lipoprotein cholesterol $(<40 \mathrm{mg} / \mathrm{dL}$ in men and $<50 \mathrm{mg} / \mathrm{dL}$ in women) [10]. Patients were excluded if they had acute coronary events, kidney failure (creatinine $>2 \mathrm{mg} / \mathrm{dL}$ ), left main coronary artery disease, chronic total occlusion, any contraindication of aspirin, clopidogrel or ACE-I treatment, increased levels of baseline creatine kinase-myocardial band (CK-MB) and/or troponin I, were on ACE-I < 1 month or on angiotensin receptor blocker therapy, needed the use of glycoprotein IIb/IIIa antagonists (Fig. 1).

All patients provided their written, informed consents. This study was approved by the institutional committee on human research and registered at ClinicalTrials.gov (identifier: NCT02054390).

We presumed an $18 \%$ incidence of primary endpoints according to the previous studies in

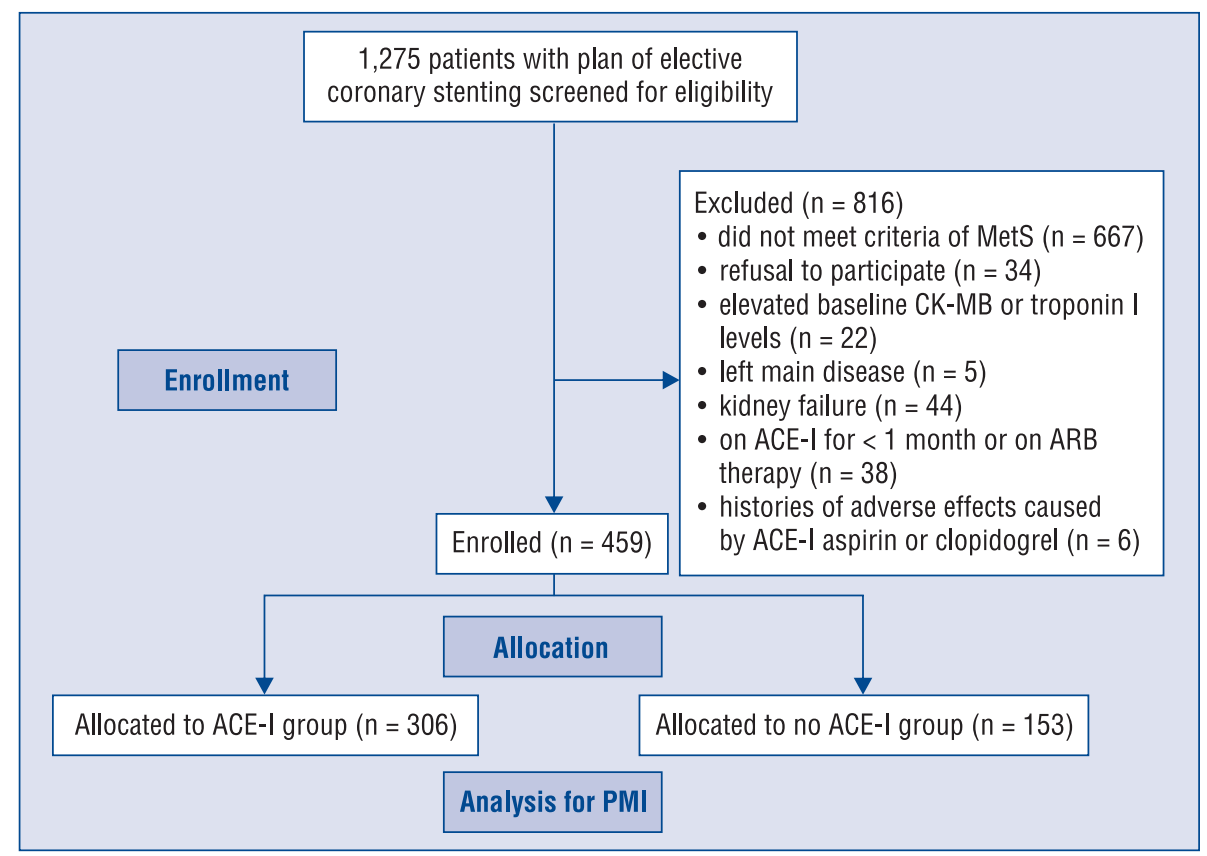

Figure 1. Flow diagram of patients. The diagram includes detailed information on the excluded patients; ACE-I angiotensin converting enzyme inhibitor; ARB — angiotensin receptor blocker; CK-MB — creatine kinase myocardial band; MetS - metabolic syndrome; PMI — periprocedural myocardial infarction. 
the control group and prospectively decided on an allocation ratio of $2 / 1$. The total sample size of 410 patients would provide $80 \%$ power to detect $50 \%$ reduction of the rate in patients who received ACE-I with an alpha level of 0.05 . We recruited 459 patients with MetS, of which 306 were under chronic ACE-I, and 153 were ACE-I naive.

The chronic ACE-I use was defined as more than 1 month of ACE-I treatment. Types of ACE-I used were ramipril $(n=135)$, perindopril $(n=96)$, lisinopril $(\mathrm{n}=59)$ and trandolapril $(\mathrm{n}=16)$. All patients received $300 \mathrm{mg}$ of clopidogrel as a loading dose at least $12 \mathrm{~h}$ before the procedure and $75 \mathrm{mg} / \mathrm{d}$ maintenance dose thereafter. During the intervention, an intravenous bolus of weight-adjusted unfractionated heparin with a targeted activated clotting time of 250-300 s was administered. Extra pre- or post-dilatation with a balloon, or intracoronary nitrate administration for maximal epicardial vasodilation were left at the discretion of the operator. As a final step, stenting was performed.

To assess the effect of ACE-I treatment on the incidence of PMI, measurements of cardiac biomarkers were performed at baseline and $24 \mathrm{~h}$ after the procedure. CK-MB and troponin I were measured by chemiluminescence immunoassays on automated analyzers (Access, Beckman Coulter, Fullerton, CA). The upper limits of normal (ULN) were defined as the $99^{\text {th }}$ percentile of the normal population according to the European Society of Cardiology/American College of Cardiology Foundation/American Heart Association/World Heart Federation universal definition [14]. Laboratory ULN was $6.3 \mathrm{ng} / \mathrm{mL}$ for CK-MB mass and $0.04 \mathrm{ng} / \mathrm{mL}$ for troponin I. The primary outcome measure was PMI that was defined as cardiac troponin I release of $>5$ times ULN $24 \mathrm{~h}$ after PCI. The secondary outcome measure was periprocedural myocardial injury that was defined as cardiac troponin I release of $>1 \times$ ULN $24 \mathrm{~h}$ after PCI. The operators who performed the stenting procedure and the laboratory staff who measured cardiac biomarkers were blinded to treatment groups.

\section{Statistical analysis}

All analyses were performed using an SPSS software package (version 20 for Windows, SPSS Inc., Chicago, IL). Data are expressed as frequencies and percentages for discrete variables and as means \pm standard deviation for continuous variables. Distributions of data were assessed by the Shapiro-Wilk test. Continuous variables were compared by Student's unpaired t-test or Mann-Whitney U-test according to the distribution of data. The $\chi^{2}$ analysis or Fisher's exact test was used to assess the significance of differences between dichotomous variables. In univariate logistic regression analysis; age, sex, body mass index, presentation of hypertension, diabetes, family history of coronary artery disease, history of myocardial infarction, serum creatinine level, plasma levels of total cholesterol, low- and high-density lipoprotein and triglyceride before the procedure, use of statins, beta-blockers, calcium channel blockers, nitrates, angiographic and procedural variables including the lesion morphology, a multivessel intervention, use of drug-eluting stents, total stent length, stent diameter, number of implanted stents, maximum balloon inflation time, maximum balloon inflation pressure and treatment assignment were assessed. Univariate correlates of periprocedural infarction with a $\mathrm{p}$ value $<0.1$ plus terms for age and gender (due to their well-established association with heart disease) were included in the multiple logistic regression analyses for odds ratios (OR) and 95\% confidence intervals (CI). Results with a p value $<0.05$ were considered significant.

\section{Results}

Among 1,275 patients screened for the study, 816 patients were excluded for various reasons (Fig. 1). Therefore, a total of 459 patients fulfilling the inclusion criteria were recruited to chronic ACE-I treatment and ACE-I naive groups in a 2/1 ratio. Comparisons of different demographic, clinical and angiographic characteristics are shown in Table 1 . Participants were mainly male (74\%) with a mean age of 61 years. The patients in the ACE-I group had a trend toward higher baseline prevalence of hypertension $(\mathrm{p}=0.09)$, diabetes mellitus $(\mathrm{p}=0.07)$ and previous myocardial infarction $(p=0.07)$. The number of stents implanted per patient tended to be higher in ACE-I treatment group $(\mathrm{p}=0.06)$.

None of the patients died in the hospital. All patients enrolled in the study underwent successful stent implantation. The overall rate of the primary outcome, defined as cardiac troponin I release of $>5$ times ULN $24 \mathrm{~h}$ after PCI was $7.4 \%$ (34 patients) among the whole population. The incidence of periprocedural myocardial injury, which is the secondary outcome measure was $18.5 \%$ (85 patients). Troponin I levels were significantly correlated with CK-MB levels $24 \mathrm{~h}$ after $\mathrm{PCI}(\mathrm{r}=0.54$, $\mathrm{p}<0.01)$. Baseline troponin I and CK-MB levels were similar in both treatment groups, whereas 
Table 1. Baseline demographic, clinical and angiographic characteristics of patients.

\begin{tabular}{|c|c|c|c|}
\hline Characteristics & ACE-I group $(n=306)$ & ACE-I naive group $(n=153)$ & $\mathbf{P}$ \\
\hline Age [years] & $61.6 \pm 9.8$ & $59.9 \pm 9.5$ & 0.09 \\
\hline Male sex & $223(72.9 \%)$ & $115(75.2 \%)$ & 0.65 \\
\hline Hypertension & $241(78.8 \%)$ & $109(71.2 \%)$ & 0.09 \\
\hline Diabetes mellitus & $124(40.5 \%)$ & $55(35.9 \%)$ & 0.07 \\
\hline Family history of CAD & $114(37.3 \%)$ & $59(38.6 \%)$ & 0.82 \\
\hline Current smoker & $120(39.2 \%)$ & $70(45.7 \%)$ & 0.19 \\
\hline Fasting blood glucose [mg/dL] & $133.5 \pm 62.2$ & $128.1 \pm 58.6$ & 0.48 \\
\hline Creatinine $[\mathrm{mg} / \mathrm{dL}]$ & $1.02 \pm 0.33$ & $1.09 \pm 0.36$ & 0.28 \\
\hline Total cholesterol $[\mathrm{mg} / \mathrm{dL}]$ & $177.8 \pm 51.0$ & $184.3 \pm 54.1$ & 0.25 \\
\hline LDL cholesterol [mg/dL] & $102.9 \pm 37.2$ & $106.8 \pm 45.8$ & 0.38 \\
\hline HDL cholesterol [mg/dL] & $41.8 \pm 10.2$ & $40.4 \pm 9.8$ & 0.47 \\
\hline Triglyceride [mg/dL] & $179.6 \pm 103.4$ & $194.4 \pm 107.6$ & 0.22 \\
\hline Previous MI & $116(37.9 \%)$ & $45(29.4 \%)$ & 0.07 \\
\hline Previous CABG & $46(15 \%)$ & $17(11.1 \%)$ & 0.26 \\
\hline LVEF [\%] & $61 \pm 11$ & $62 \pm 11$ & 0.58 \\
\hline Beta-blockers & $226(73.9 \%)$ & $105(68.6 \%)$ & 0.23 \\
\hline Statins & $264(86.3 \%)$ & $122(79.7 \%)$ & 0.08 \\
\hline Nitrate & $178(58.2 \%)$ & $85(55.6 \%)$ & 0.56 \\
\hline Calcium channel blockers & $20(6.5 \%)$ & $13(8.5 \%)$ & 0.44 \\
\hline Multivessel intervention & $89(29.1 \%)$ & $34(22.2 \%)$ & 0.36 \\
\hline Lesion type B2/C & $115(37.6 \%)$ & $54(35.3 \%)$ & 0.88 \\
\hline Number of stents per patient & $1.7 \pm 0.9$ & $1.5 \pm 0.8$ & 0.06 \\
\hline Number of DES per patient & $0.54 \pm 0.34$ & $0.47 \pm 0.38$ & 0.44 \\
\hline LAD artery & $152(49.7 \%)$ & $69(45.1 \%)$ & 0.33 \\
\hline Saphenous graft & $6(2 \%)$ & $3(2 \%)$ & 0.88 \\
\hline Length of stent $[\mathrm{mm}]$ & $21.4 \pm 11.4$ & $18.4 \pm 8.1$ & 0.10 \\
\hline Diameter of stent [mm] & $2.9 \pm 0.4$ & $2.9 \pm 0.4$ & 0.84 \\
\hline Side branch occlusion & $17(5.6 \%)$ & $8(5.3 \%)$ & 0.76 \\
\hline
\end{tabular}

ACE-I — angiotensin converting enzyme inhibitor; CABG — coronary artery bypass graft; CAD — coronary artery disease, DES — drug eluting stent, HDL - high density lipoprotein; LAD — left anterior descending; LDL — low density lipoprotein; LVEF — left ventricular ejection fraction; $\mathrm{MI}$-myocardial infarction

Table 2. Myocardial necrosis markers at baseline and 24 hours after the procedure.

\begin{tabular}{lccc}
\hline Biomarker: Median (IOR) $[\mathrm{ng} / \mathrm{mL}]$ & ACE-I group $(\mathbf{n}=\mathbf{3 0 6})$ & ACE-I naive group $(\mathbf{n}=\mathbf{1 5 3})$ & $\mathbf{P}$ \\
\hline Baseline troponin I & $0.02(0.02-0.03)$ & $0.02(0.02-0.03)$ & 0.69 \\
Baseline CK-MB & $3.3(1.7-4.0)$ & $3.4(1.7-4.0)$ & 0.64 \\
Troponin I at 24 h & $0.03(0.02-0.03)$ & $0.04(0.03-0.04)$ & 0.03 \\
CK-MB at 24 h & $4.1(2.3-5.8)$ & $5.7(3.8-6.2)$ & 0.04 \\
\hline
\end{tabular}

ACE-I — angiotensin converting enzyme inhibitor; CK-MB — creatinine kinase myocardial band; IQR — interquartile range

biomarkers were significantly lower in ACE-I group $24 \mathrm{~h}$ after the procedure, indicating that more protection was conferred by ACE-I treatment (Table 2). Rates of PMI and injury are shown in
Figure 2. Chronic ACE-I therapy provided 5.5\% of absolute risk reduction (ARR) and $49.5 \%$ of relative risk reduction (RRR) for PMI. Benefits of ACE-I on secondary outcome measure were $8.5 \%$ 


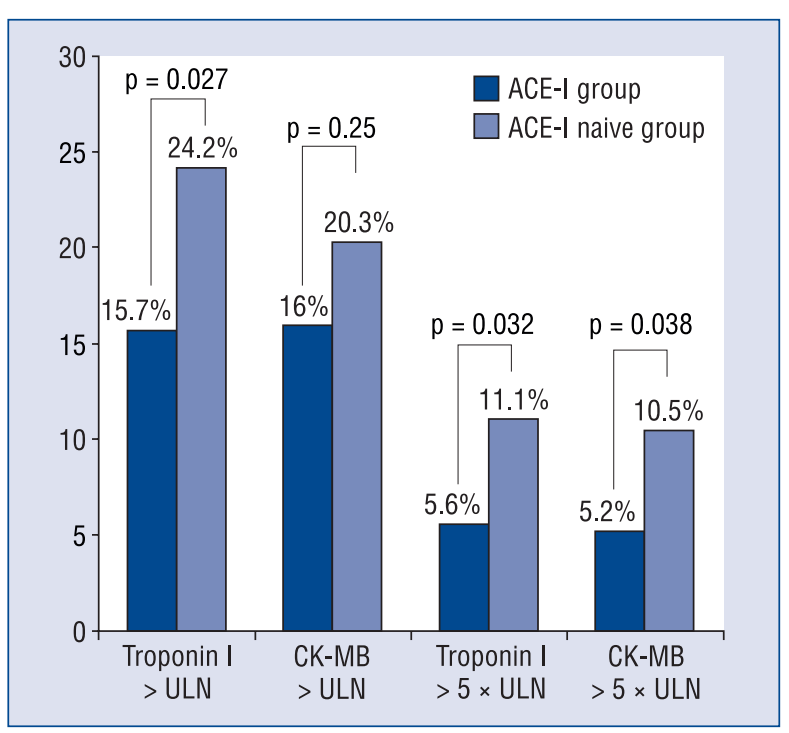

Figure 2. Comparisons of incidences of periprocedural myocardial infarction, defined as increase in troponin I and creatinine kinase myocardial band (CK-MB) 5 times the upper normal limit, and periprocedural myocardial injury, defined as increase in troponin I and CK-MB above the upper normal limit between the chronic angiotensin converting enzyme inhibitor (ACE-I; $n=306$ ) and ACE-I naive ( $n=153$ ) groups; ULN - upper limit normal.

for ARR and $35.2 \%$ for RRR (Fig. 2). Increase in frequency of PMI in the ACE-I naive group also translated to an increase in the length of hospital stay $(3.5 \pm 1.2$ vs. $2.0 \pm 0.6$ days among patients with and without PMI, respectively, $\mathrm{p}<0.001$ ). Patients in the ACE-I group had shorter duration of hospital stay than those in the ACE-I naive group ( $1.9 \pm 0.7$ vs. $2.2 \pm 0.9$ days, respectively, $\mathrm{p}=0.03)$. The influence of ACE-I therapy on PMI was examined by comparing the hazard ratio of various factors described previously. Univariate analysis identified body mass index, low density lipoprotein cholesterol, nitrate and ACE-I use as significant factors for the development of PMI. Multivariate regression model revealed that body mass index increased and use of nitrate and ACE-I decreased the probability of PMI independent from confounding factors (OR 1.14, 95\% CI 1.05-1.23, $\mathrm{p}=0.002$ for body mass index, OR $0.26,95 \% \mathrm{CI}$ $0.14-0.48, \mathrm{p}=0.01$ for nitrate use, OR $0.51,95 \%$ CI $0.27-0.93, \mathrm{p}=0.03$ for ACE-I use) (Table 3 ). No difference was observed in the incidence of PMI between various ACE-I drugs (Table 4). Four (1.3\%) patients reached the maximal dose of ACE-I and $205(67 \%)$ patients reached the at least $50 \%$ of maximal dose of ACE-I.

\section{Discussion}

The current prospective cohort study demonstrated a lower risk of PMI among patients with MetS, who were under chronic ACE-I therapy (OR $0.51,95 \%$ CI 0.27-0.93). Significant decreases in the incidences of both PMI and injury were provided by ACE-I treatment $(\mathrm{p}=0.032$ and $\mathrm{p}=0.027$, respectively).

Existing studies have yielded inconsistent data on whether MetS increases the risk of cardiovascular events after PCI [15-18]. However, a recent meta-analysis stated MetS as an important risk factor following stent implantation [5].

Renin-angiotensin system is regulated by hyperlipidemia, hyperglycemia and obesity, which are components of MetS and it is also a therapeutic target for several risk factors associated with MetS [19]. Although the data from the clinical studies are limited, ACE-I are known to have favorable effects on patients with MetS [20,21]. Their effects on PMI were not assessed. Therefore, we sought to determine whether ACE-I therapy prevents PMI among patients with MetS, who underwent elective coronary stenting.

ACE-I therapy is known to be beneficial in patients with coronary atherosclerotic disease [22, 23]. The cardioprotective effects of intracoronary ACE-I therapy during coronary angioplasty were described previously among patients with stable coronary artery disease [24] and acute myocardial infarction [25]. The favorable effects of ACE-I may be due to increased endogenous bradykinin activity which mediates improvement of the endotheliumdependent epicardial vasomotion [26]. ACE-I were also shown to improve coronary microvascular functions and protect the myocardium from the procedure-related injury during PCI [24, 27]. Our data extended these previous findings by demonstrating that treatment with ACE-I therapy before PCI was associated with a lower incidence of PMI, defined as the elevation of troponin I or CK-MB values $>5$ times ULN, among patients with MetS.

PCI may cause PMI by formation of distal microembolization and induction of reperfusion injury of the ischemic myocardium. PMI is associated with adverse events and poor prognosis. Several risk factors are associated with PMI and include patient characteristics, lesion related and procedure-related factors [28]. Rates of hypertension, diabetes mellitus, prior myocardial infarction and number of stents per patient were insignificantly higher among patients under chronic ACE-I treatment. First three of these risk factors 
Table 3. Univariate and multivariate logistic regression analyses for periprocedural myocardial infarction.

\begin{tabular}{|c|c|c|c|c|c|c|}
\hline \multirow[t]{2}{*}{ Variable } & \multicolumn{3}{|c|}{ Univariate } & \multicolumn{3}{|c|}{ Multivariate } \\
\hline & Odds ratio & $95 \% \mathrm{Cl}$ & $\mathbf{P}$ & Odds ratio & $95 \% \mathrm{Cl}$ & $\mathbf{P}$ \\
\hline Age & 1.01 & $0.98-1.05$ & 0.47 & 0.98 & $0.95-1.01$ & 0.22 \\
\hline Female & 1.46 & $0.63-3.38$ & 0.38 & 1.21 & $0.58-2.52$ & 0.61 \\
\hline Body mass index & 1.29 & $1.02-1.77$ & 0.007 & 1.14 & $1.05-1.23$ & 0.002 \\
\hline Hypertension & 0.96 & $0.42-2.20$ & 0.92 & & & \\
\hline Diabetes mellitus & 0.90 & $0.54-1.50$ & 0.69 & & & \\
\hline Family history & 0.91 & $0.47-1.79$ & 0.79 & & & \\
\hline Current smoker & 0.89 & $0.55-1.44$ & 0.64 & & & \\
\hline History of MI & 1.19 & $0.58-2.45$ & 0.63 & & & \\
\hline Creatinine & 1.05 & $0.56-1.97$ & 0.87 & & & \\
\hline Total cholesterol & 1.01 & $0.98-1.03$ & 0.49 & & & \\
\hline HDL cholesterol & 0.99 & $0.97-1.02$ & 0.67 & & & \\
\hline LDL cholesterol & 1.03 & $1.01-1.05$ & 0.04 & 0.99 & 0.99-1.01 & 0.69 \\
\hline Triglyceride & 0.99 & $0.99-1.01$ & 0.58 & & & \\
\hline Statin & 0.65 & $0.35-1.32$ & 0.09 & 0.84 & $0.37-1.91$ & 0.68 \\
\hline Beta-blocker & 1.35 & $0.79-2.38$ & 0.16 & & & \\
\hline ССВ & 2.01 & $0.65-6.44$ & 0.22 & & & \\
\hline Nitrate & 0.49 & $0.24-0.88$ & 0.03 & 0.26 & $0.14-0.48$ & 0.01 \\
\hline Lesion B2/C & 1.21 & $0.86-1.89$ & 0.06 & 1.20 & $0.67-2.20$ & 0.53 \\
\hline Multivessel intervention & 1.09 & $0.44-2.68$ & 0.85 & & & \\
\hline DES use & 1.31 & $0.84-2.06$ & 0.24 & & & \\
\hline Stent length & 1.01 & $0.96-1.06$ & 0.72 & & & \\
\hline Stent diameter & 0.53 & $0.23-1.22$ & 0.13 & & & \\
\hline Number of stents & 0.76 & $0.33-1.77$ & 0.52 & & & \\
\hline Balloon inflation time & 1.06 & $0.93-1.16$ & 0.42 & & & \\
\hline Balloon inflation pressure & 0.89 & $0.74-1.08$ & 0.24 & & & \\
\hline ACE-I use & 0.48 & $0.23-0.87$ & 0.02 & 0.51 & $0.27-0.93$ & 0.03 \\
\hline
\end{tabular}

ACE-I — angiotensin converting enzyme inhibitor; CCB — calcium channel blockers; $\mathrm{Cl}$ — confidence interval; DES — drug-eluting stent; $\mathrm{HDL}$ - high density lipoprotein; CK-MB — creatinine kinase myocardial band; MI - myocardial infarction; LDL - low density lipoprotein

Table 4. Incidences of periprocedural myocardial injury and myocardial infarction according to the various types of angiotensin converting enzyme inhibitor drugs.

\begin{tabular}{lccccc}
\hline & $\begin{array}{c}\text { Ramipril } \\
(\mathbf{n}=\mathbf{1 3 5})\end{array}$ & $\begin{array}{c}\text { Perindopril } \\
(\mathbf{n}=\mathbf{9 6})\end{array}$ & $\begin{array}{c}\text { Lisinopril } \\
(\mathbf{n}=\mathbf{5 9 )}\end{array}$ & $\begin{array}{c}\text { Trandolapril } \\
(\mathbf{n}=\mathbf{1 6})\end{array}$ & $\mathbf{P}$ \\
\hline Troponin I > ULN & $22(16.3 \%)$ & $13(13.5 \%)$ & $10(16.9 \%)$ & $3(18.8 \%)$ & 0.96 \\
CK-MB > ULN & $21(15.6 \%)$ & $13(13.5 \%)$ & $11(18.6 \%)$ & $4(25 \%)$ & 0.63 \\
Troponin I > 5 $\times$ ULN & $9(6.7 \%)$ & $4(4.2 \%)$ & $3(5.1 \%)$ & $1(6.3 \%)$ & 0.87 \\
CK-MB > 5 $\times$ ULN & $8(5.9 \%)$ & $4(4.2 \%)$ & $3(5.1 \%)$ & $1(6.3 \%)$ & 0.94 \\
\hline
\end{tabular}

CK-MB — creatinine kinase myocardial band; ULN — upper limit normal

are patient-related risk factors, and the last one is procedure-related risk factor for PMI. Even the rates of these components tended to be higher among patients under ACE-I therapy, rate of PMI was observed lower in this group. Other patient characteristics, lesion related risk factors and procedural features were similar between ACE-I treatment and naive groups. Although investigating 
the difference between various types of the ACE-I is beyond the scope of this trial, we noted no difference between 4 types of ACE-I. The positive effect of ACE-I may be considered a class effect.

\section{Conclusions}

There is little data in the literature suggesting that ACE-I given periprocedurally are cardioprotective. In conclusion, this prospective observational cohort study demonstrated that the chronic ACE-I therapy was an independent predictor for reduced PMI among patients with MetS who underwent elective coronary intervention. These results generate hypothesis if all patients with MetS should be on ACE-I therapy. Prospective randomized trials are needed to test this hypothesis.

\section{Conflict of interest: None declared}

\section{References}

1. Eckel RH, Grundy SM, Zimmet PZ. The metabolic syndrome. Lancet, 2005; 365: 1415-1428.

2. Isomaa B, Almgren $\mathrm{P}$, Tuomi $\mathrm{T}$ et al. Cardiovascular morbidity and mortality associated with the metabolic syndrome. Diabetes Care, 2001; 24: 683-689.

3. Ford ES. The metabolic syndrome and mortality from cardiovascular disease and all-causes: Findings from the National Health and Nutrition Examination Survey II Mortality Study. Atherosclerosis, 2004; 173: 309-314.

4. Reaven G. The metabolic syndrome or the insulin resistance syndrome? Different names, different concepts, and different goals. Endocrinol Metabolism Clin North Am, 2004; 33: 283-303.

5. $\mathrm{Xu} \mathrm{D}$, Guo $\mathrm{Y}$, Wang $\mathrm{H}$ et al. The angiographic and clinical outcomes after coronary stenting in patients with metabolic syndrome. Atherosclerosis, 2012; 221: 416-421.

6. Califf RM, Abdelmeguid AE, Kuntz RE et al. Myonecrosis after revascularization procedures. J Am Coll Cardiol, 1998; 31: 241-251.

7. Pervaiz MH, Sood P, Sudhir K et al. Periprocedural myocardial infarction in a randomized trial of everolimus-eluting and Paclitaxel-eluting coronary stents: Frequency and impact on mortality according to historic versus universal definitions. Circ Cardiovasc Interv, 2012; 5: 150-156.

8. Ioannidis JP, Karvouni E, Katritsis DG. Mortality risk conferred by small elevations of creatine kinase-MB isoenzyme after percutaneous coronary intervention. J Am Coll Cardiol, 2003; 42: 1406-1411.

9. Kini AS, Lee P, Marmur JD et al. Correlation of post percutaneous coronary intervention creatine kinase-MB and troponin I elevation in predicting mid-term mortality. Am J Cardiol, 2004; 93: 18-23.

10. Grundy SM, Brewer HB, Jr., Cleeman JI, Smith SC, Lenfant C; American Heart Association, National Heart, Lung, Blood, Institute. Definition of metabolic syndrome: Report of the National Heart, Lung, and Blood Institute/American Heart Association conference on scientific issues related to definition. Circulation, 2004; 109: 433-438.

11. Shahin Y, Khan JA, Samuel N, Chetter I. Angiotensin converting enzyme inhibitors effect on endothelial dysfunction: A metaanalysis of randomised controlled trials. Atherosclerosis, 2011; 216: 7-16.
12. McAlister FA, Renin-Angiotensin System Modulator Meta-Analysis I. Angiotensin-converting enzyme inhibitors or angiotensin receptor blockers are beneficial in normotensive atherosclerotic patients: A collaborative meta-analysis of randomized trials. Eur Heart J, 2012; 33: 505-514.

13. Patarroyo Aponte MM, Francis GS. Effect of Angiotensin-converting enzyme inhibitors and Angiotensin receptor antagonists in atherosclerosis prevention. Curr Cardiol Rep, 2012; 14: 433-442 .

14. Thygesen K, Alpert JS, Jaffe AS, Simoons ML, Chaitman BR, White HD. ESC Committee for Practice Guidelines (CPG). Third universal definition of myocardial infarction. Eur Heart J, 2012; 33: 2551-2567.

15. Rana JS, Monraats PS, Zwinderman AH et al. GENDER study. Metabolic syndrome and risk of restenosis in patients undergoing percutaneous coronary intervention. Diabetes Care, 2005; 28: 873-877.

16. Kim JS, Lee HC, Choi BK et al. Impact of metabolic syndrome on in-stent restenosis and clinical outcomes after percutaneous coronary stent implantation. Diabetes Res Clin Pract, 2010; 88: e38-e41.

17. Bin $H$, Yujie $Z$, Yuyang $L$ et al. Impact of metabolic syndrome on clinical outcomes after drug-eluting stent implantation in patients with coronary artery disease. Angiology, 2011; 62: 440-446.

18. Hoffmann R, Stellbrink E, Schroder J et al. Impact of the metabolic syndrome on angiographic and clinical events after coronary intervention using bare-metal or sirolimus-eluting stents. Am J Cardiol, 2007; 100: 1347-1352.

19. Putnam K, Shoemaker R, Yiannikouris F, Cassis LA. The reninangiotensin system: A target of and contributor to dyslipidemias, altered glucose homeostasis, and hypertension of the metabolic syndrome. Am J Physiol Heart and Circ Physiol, 2012; 302: H1219-1230.

20. Khan BV, Sola S, Lauten WB et al. Quinapril, an ACE inhibitor, reduces markers of oxidative stress in the metabolic syndrome. Diabetes Care, 2004; 27: 1712-1715.

21. Anichkov DA, Shostak NA, Schastnaya OV. Comparison of rilmenidine and lisinopril on ambulatory blood pressure and plasma lipid and glucose levels in hypertensive women with metabolic syndrome. Curr Med Res Opin, 2005; 21: 113-119.

22. Yusuf S, Sleight P, Pogue J, Bosch J, Davies R, Dagenais G. Effects of an angiotensin-converting-enzyme inhibitor, ramipril, on cardiovascular events in high-risk patients. The Heart Outcomes Prevention Evaluation Study Investigators. N Engl J Med, 2000; 342: 145-153.

23. Fox KM, Investigators EUtOrocewPiscAd. Efficacy of Perindopril in reduction of cardiovascular events among patients with stable coronary artery disease: Randomised, double-blind, placebocontrolled, multicentre trial (the EUROPA study). Lancet, 2003; 362: 782-788.

24. Leesar MA, Jneid H, Tang XL, Bolli R. Pretreatment with intracoronary enalaprilat protects human myocardium during percutaneous coronary angioplasty. J Am Coll Cardiol, 2007; 49: $1607-1610$.

25. Schaefer U, Kurz T, Bonnemeier $\mathrm{H}$ et al. Intracoronary enalaprilat during angioplasty for acute myocardial infarction: Alleviation of post-ischaemic neurohumoral and inflammatory stress? J Intern Med, 2007; 261: 188-200.

26. Prasad A, Husain S, Quyyumi AA. Abnormal flow-mediated epicardial vasomotion in human coronary arteries is improved by angiotensin-converting enzyme inhibition: A potential role of bradykinin. J Am Coll Cardiol, 1999; 33: 796-804.

27. Mangiacapra F, Peace AJ, Di Serafino L et al. Intracoronary EnalaPrilat to Reduce MICROvascular Damage During Percutaneous Coronary Intervention (ProMicro) study. J Am Coll Cardiol, 2013; 61: 615-621.

28. Herrmann J. Peri-procedural myocardial injury: 2005 update. Eur Heart J, 2005; 26: 2493-2519. 